\section{INFLUENCIA FENICIA EN LA ARQUITECTURA ANTIGUA DE NIEBLA (HUELVA)}

\author{
PHOENICIAN INFLUENCES ON THE \\ ANCIENT ARCHITECTURE OF NIEBLA \\ (HUELVA)
}

\author{
MARIA BELEN (*) \\ JOSE LUIS ESCACENA $(*)$
}

\section{RESUMEN}

Las excavaciones practicadas en Niebla (provincia de Huelva, España) junto a la "Puerta de Sevilla" han descubierto un tell protohistórico sobre el que se asienta la ciudad actual. Dos de los edificios encontrados destacan por sus técnicas de clara inspiración fenicia.

El presente trabajo aborda el estudio tipológico de dichas obras, así como su cronología, enmarcándolas en el contexto de la colonización fenicia del Mediterráneo occidental y reflexionando sobre su significado en los procesos de aculturación experimentados por la Península Ibérica durante la Edad del Hierro.

\begin{abstract}
In the excavations realized in the city of Niebla (Huelva, Spain), next to the "Puerta de Sevilla", a protohistoric tell was found under the present village. Two buildings uncovered in these excavations have techniques inspired in the Phoenician world.

This article deals with the typological and chronological study of those buildings in the context of Phoenician colonization of the Western Mediterranean, and reflects on their significance in the process of cultural change in the Iberian Peninsula during the Iron Age.

Palabras clave: Protohistoria. Andalucía occidental. Fenicios. Arquitectura. Técnicas de construcción. Muros de pilares.

Key words: Protohistory. Western Andalusia. Phoenician. Architecture. Building techniques. Pillars walls.
\end{abstract}

(*) Departamento de Prehistoria y Arqueología. Universidad de Sevilla. Sevilla.

\section{INTRODUCCION}

A poco de comenzar el I Milenio a. C., las aldeas del Bajo Guadalquivir empezaron a experimentar importantes transformaciones, que supusieron con el tiempo la implantación de una auténtica estructura urbana. Los investigadores están de acuerdo en que todos estos cambios, que afectaron a la configuración de los poblados en una amplia región del sur y sureste de la Península Ibérica, están relacionados con la presencia de gentes procedentes del Mediterráneo oriental (cf. Almagro y otros, 1990: 284; Bendala, 1989: 141; González Prats, 1983: 272; Ros Sala, 1989: 164). Primero se vio que a partir de la segunda mitad del siglo VIII a. C. empezaban a difundirse concepciones nuevas del espacio doméstico. Las cabañas circulares tradicionales, dispersas por todo el área del poblado, se iban paulatinamente substituyendo por viviendas de muros rectos, rectangulares o cuadradas, alineadas ordenadamente en manzanas abiertas a calles o plazas, según los modelos implantados en las colonias fenicias de la costa mediterránea andaluza desde la primera mitad de dicho siglo (Aubet, 1986: 18). Después se fueron documentando en los poblados de las tierras interiores del Guadalquivir los mismos sistemas de fortificación que en los asentamientos coloniales. El foso de sección triangular de Toscanos (Niemeyer, 1986: 116) presenta analogías con el que se halló posteriormente en el Castillo de Doña Blanca (Ruiz Mata, 1988: 41) 
y con los más recientes de Carmona (Cardenete y Lineros, 1990: 269-270, fotos 2 y 3, lám. 4). Ahora se habla ya de santuarios (Blázquez, 1991: 37; Llobregat, 1991: 328) y de grandes complejos palaciales de inspiración oriental (Almagro-Gorbea y otros, 1990: 277; Celestino, 1991: 190); y se sostiene incluso que algunos poblados, como el de Tejada la Vieja (Huelva), sin ser fenicios, se proyectaron bajo inspiración y totalmente de acuerdo con modelos fenicios (Fernández Jurado, 1991: 173).

Pero, aunque poco a poco se van añadiendo nuevos datos, seguimos sin saber gran cosa de la arquitectura del período que transcurre entre el siglo VIII a. C. y la decadencia del mundo tartésico, a fines del siglo VI a. C. El panorama empeora si pretendemos indagar en aspectos más específicos. Empezamos a comprobar que no sólo se trasplantan los modelos conceptuales de las ciudades, las casas o los palacios orientales, sino también las técnicas de construcción; pero está todavía por hacer un estudio pormenorizado de tales técnicas y, en general, ni siquiera contamos con descripciones adecuadas que permitan distinguir las diferentes tradiciones constructivas.

El trabajo que presentamos no pasa de ser una modesta aportación para la investigación de estas cuestiones. Su objetivo es dar a conocer la existencia en el yacimiento de Niebla (Huelva) de estructuras construidas con técnicas de tradición fenicia (Belén, 1986: 272 ss. y láms. I-III; Belén y Escacena, e.p.) (1).

\section{EL YACIMIENTO. LAS INVESTIGACIONES ARQUEOLOGICAS EN NIEBLA}

Niebla está situada en la provincia de Huelva, a unos $30 \mathrm{kms}$. de esta última ciudad (Fig. 1.1). Rodeada aún por la muralla medieval, se alza sobre un cerro flanquedo en sus lados oriental y meridional por el río Tinto (Fig. 1.2). La comarca es de relieve suave, con alturas de no más de 150 mts. y con tierras fértiles que permiten un buen aprovechamiento agropecuario. Al norte del término municipal afloran las

(1) Los autores agradecen la colaboración del prof. R. de Balbín, autor de la mayor parte de las fotos que ilustran este trabajo, y de Milagrosa Sánchez Andréu que pasó a tinta los dibujos sobre originales de M. Belén. pizarras que constituyen la base geológica de la estribación sur de Sierra Morena en esta zona (Borja, 1989; Terrero, 1952 y 1954).

Las condiciones estratégicas y el potencial económico de su entorno explican que el lugar se poblara con relativa continuidad ya desde el Calcolítico. Niebla constituye un auténtico cruce de caminos donde interfieren rutas que discurren en sentido norte-sur con otras que van de este a oeste. Según la tradición y la documentación arqueológica, dispuso de embarcadero fluvial en época antigua. Por ser escala en la vía de salida del mineral de Riotinto hacia el Atlántico por el puerto de Huelva, ha constituido punto de mira para conquistadores durante toda su historia. La vida continuada sobre la terraza natural primitiva ha originado un auténtico tell sobre el que reposa la población actual.

Algunas investigaciones permiten reconstruir a grandes rasgos las etapas más antiguas de la historia de Niebla. Consta que la zona se ocupó al menos desde el Paleolítico Medio (Vallespí y otros, 1986: 44 y 52-54), período al que siguió un vacío poblacional documentado en el resto de los tiempos pleistocénicos, como de hecho parece que sucedió en gran parte de Andalucía occidental (Fortea, 1986: 68-73). Empieza a tenerse, no obstante, mayor conocimiento del Neolítico, gracias sobre todo al yacimiento de La Dehesa, en la cercana localidad de Lucena Del Puerto (Piñón y Bueno, 1985: 110-115). Para la fase calcolítica, Niebla y sus alrededores han suministrado una valiosa información, a la vez que monumentos megalíticos como el Dolmen de Soto (Obermaier, 1924) y el tholos de El Moro (Garrido y Orta, 1967). En la propia Niebla, las covachas de Los Bermejales contenían niveles de ocupación de estos tiempos (Whishaw, inédito: cap. 2, p. 12), a los que tal vez haya que atribuir también las cuevas artificiales del Cabezo Gordo (Garrido, 1971: 10). Al sur de la ciudad, en la finca denominada La Ruiza, se ha documentado asimismo un enterramiento del Bronce pleno (Del Amo, 1975: 175), contemporáneo de unas problemáticas inhumaciones en pithoi paralelizadas con las argáricas (Jurado, 1934: 183). Pero la etapa histórica de Niebla que aquí nos puede resultar más interesante es la protohistórica. A ella pertenecen los ajuares recuperados en el túmulo funerario de El Palmarón (García y 

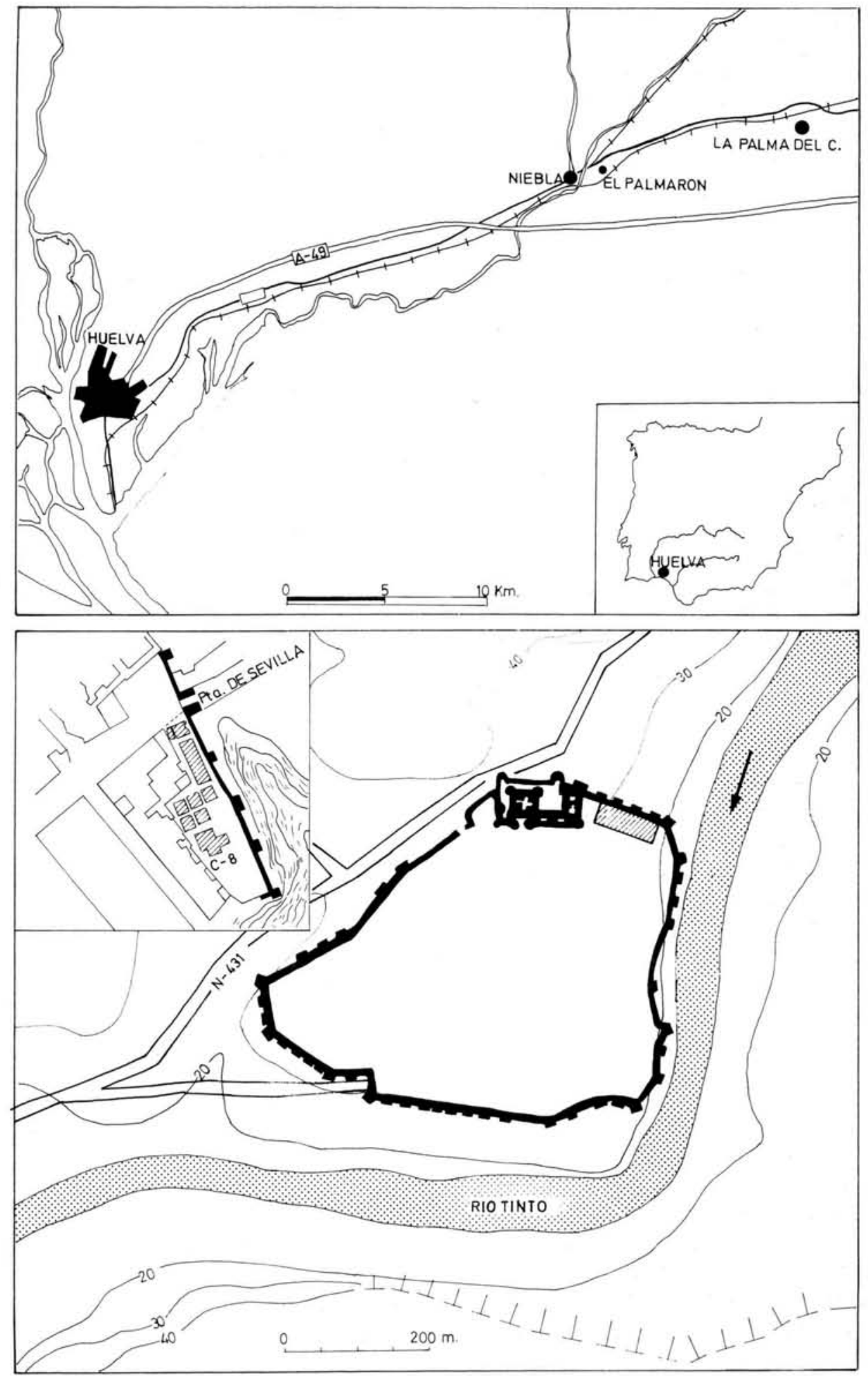

Fig. 1. Niebla (Huelva). 1: Situación. 2: La ciudad y la zona excavada junto a la Puerta de Sevilla.

T. P.. $\mathrm{n}^{\circ} 50,1993$ 
Bellido, 1960: 53). Excavaciones recientes sugieren que Niebla nació como núcleo urbano propiamente dicho hacia el siglo VII a. C. (Belén y Escacena, e.p.; Belén y otros, 1983), lo que confirma la fecha ya avanzada por Droop (1925: 39) y sospechada a través de materiales orientalizantes que han sido objeto de diversos estudios (López Roa, 1978: 177; Pingel, 1975: 120).

En conjunto, toda la documentación hasta ahora rescatada indica que, si bien pudo haber en Niebla un poblamiento anterior al de época tartésica según revelan los dispersos datos del Cobre y del Bronce, sólo a partir de la primera Edad del Hierro existió en ese punto del Tinto una población estable y con aparente continuidad poblacional hasta hoy. Por tanto, desde los testimonios del Bronce pleno hasta estos otros de la fase tartésica, la comarca de Niebla participó con toda seguridad de un vacío poblacional que tiene un reflejo más amplio en casi toda Andalucía occidental (Escacena y Belén, 1991: 24-26) y que marca un fuerte hiato en la cadena cultural de la Edad del Bronce, dejando de momento sin base sólida un supuesto origen local del mundo tartésico precolonial (Belén y Escacena, 1992). Esta problemática ha sido recogida recientemente por Bendala (1990: 1923) para explicar parecidos fenómenos observados en el área extremeña.

El hallazgo de cerámica con decoración incisa y digitada en Los Bermejales (Blanco y Luzón, 1975: 244) demuestra el ancho perímetro de la Niebla tartésica y, en consecuencia, el apogeo experimentado por la población durante la primera Edad del Hierro. Si los altibajos de la ciudad han estado ligados estrechamente a las circunstancias de explotación de la cuenca minera de Riotinto, el auge de que gozó en su más antigua protohistoria debe relacionarse tal vez con el control de la ruta de salida del mineral desde la sierra hacia el puerto de Huelva (Fernández Jurado, 1986: 168-169; Ruiz Mata, 1989: 242). De hecho, Niebla pudo haber compartido con Huelva la centralización de los recursos mineros de la región (Blanco y Rothenberg, 1981: 19). Si a esto se une la existencia de fértiles campos en sus alrededores, se obtienen circunstancias ideales para el nacimiento de una aristocracia que tal vez tuvo en el sepulcro de El Palmarón una de sus manifestaciones en torno a la muerte más importantes. De hecho, de esta sepultura procede uno de los conjuntos metálicos más ricos que hoy constituyen los ajuares funerarios tartésicos (Cerdeño, 1981: 42; Cuadrado, 1956: 56; García y Bellido, 1956: 87 y 1960: 53; Jurado, 1934: 163).

La ocupación de la ciudad durante la segunda Edad del Hierro dejó huellas evidentes en la secuencia estratigráfica (Belén y Escacena, e.p.; Belén y otros, 1983). No obstante, la documentación disponible no habla con claridad de la recesión económica ni de otros múltiples aspectos de la crisis que afectó a finales del siglo VI a. C. al mundo tartésico. La posibilidad de que, aun de forma residual, se siguieran explotando los metales de Riotinto durante la fase turdetana, ofrecería una explicación satisfactoria a la superación de una etapa de vacas flacas generalizada que acabó con el esplendor del que la Baja Andalucía había gozado durante los tiempos orientalizantes.

La Niebla romana volvió a conocer un florecimiento espectacular, de nuevo al compás de las importantes actividades minero-metalúrgicas del área de Riotinto. En este sentido, se ha escrito que, en la provincia de Huelva, sólo esta comarca de la tierra llana habría experimentado una verdadera y profunda romanización (Blanco y Rothenberg, 1981: 14-15). La información arqueológica de esta etapa empezó a recopilarse a través de hallazgos numismáticos ya en el siglo XVII al menos (Caro, 1634: 213-214), y ha sido sistematizada en un trabajo de síntesis sobre la provincia de Huelva (Luzón, 1975a y 1975b).

\section{LAS CONSTRUCCIONES DE TRADICION FENICIA EN NIEBLA: CARACTERISTICAS Y CONTEXTO ESTRATIGRAFICO}

Las estructuras que estudiamos en este artículo se hallaron en varias campañas de excavación llevadas a cabo entre 1978 y 1982 junto a la entrada a la ciudad llamada "Puerta de Sevilla", en un solar que ya había sido sondeado parcialmente con anterioridad (Garrido y Orta, 1975b: 257 y lám. 196). La zona está cerrada al norte por la cerca almorávide, y por su flanco oriental cae en talud casi vertical hasta el río Tinto (Fig. 1.2). 

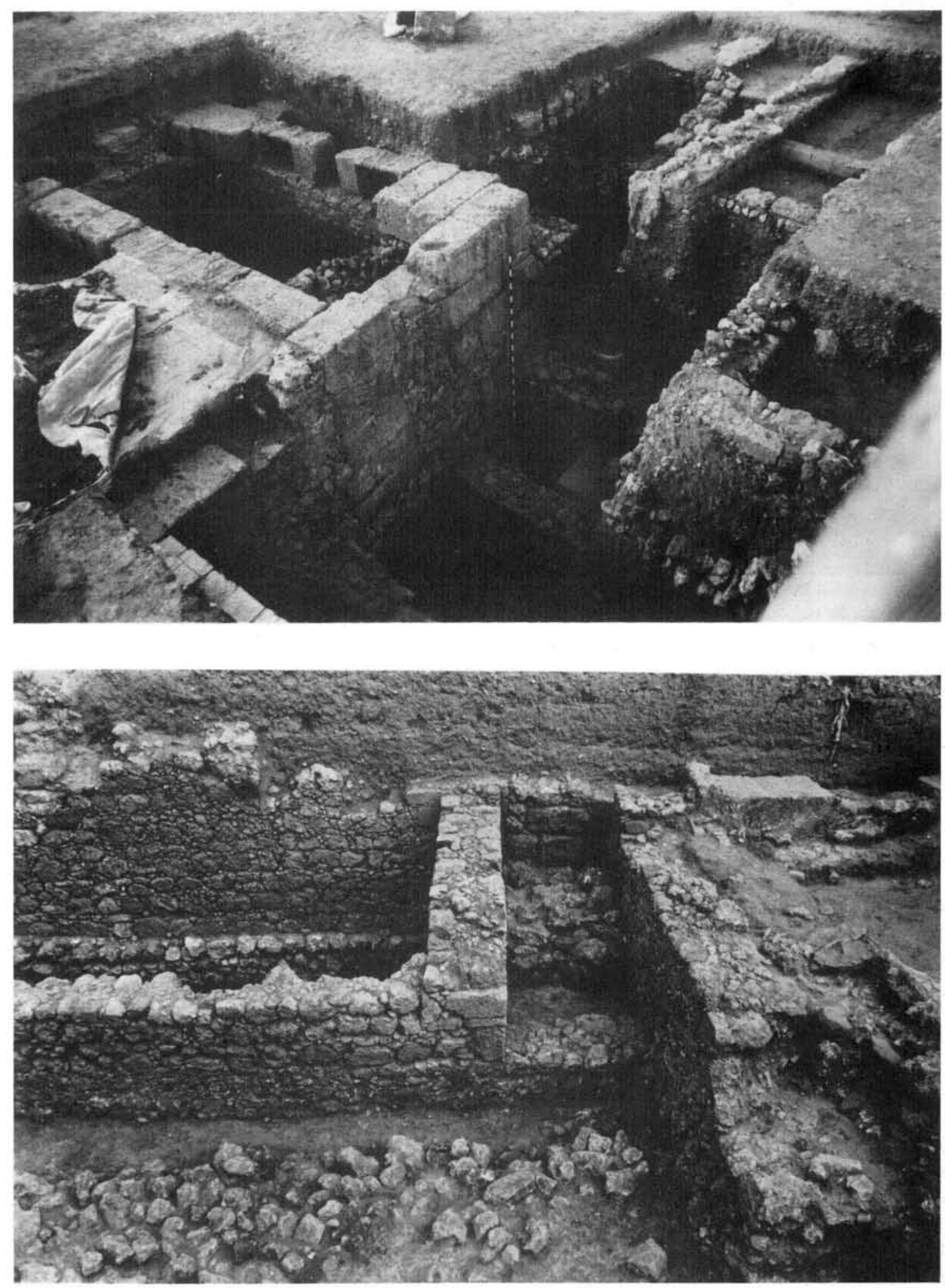

Lám. I. Niebla (Huelva). 1) Cata 8, aspecto general. 2) Cata 4, muros de técnica oriental (excavación del Prof. R. de Balbín).

T. P.. $\mathrm{n}^{\circ} 50.1993$ 


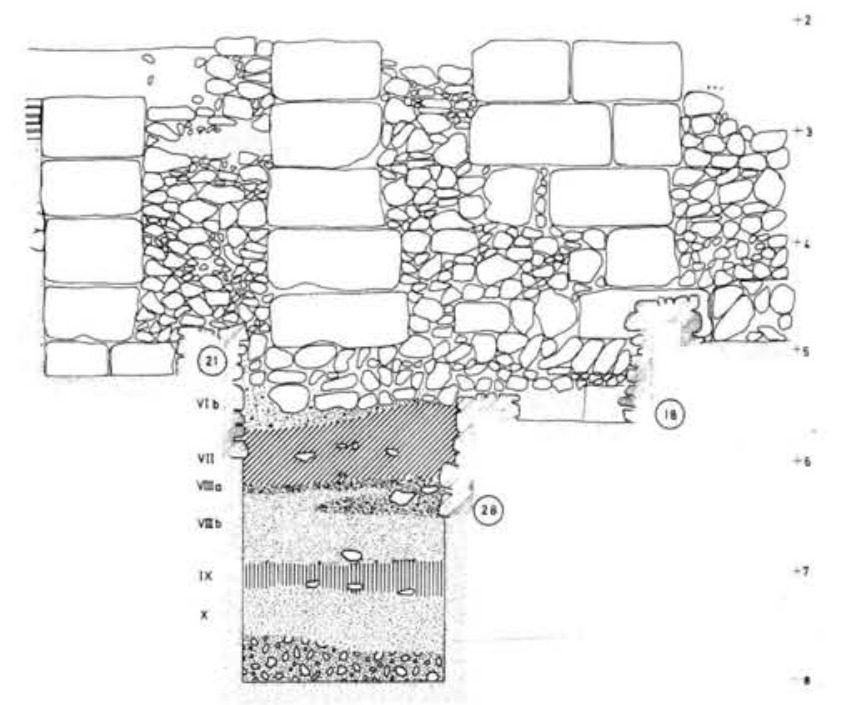

Fig. 2. Niebla (Huelva). Cata 8. Muro 5, cara Este.

Se abrieron en total diez cuadrículas. De ellas se obtuvo una secuencia de gran complejidad debido a las contínuas reocupaciones del sitio desde su primera fundación como hábitat, $\mathrm{y}$ sobre todo porque en muchas ocasiones se habían llevado a cabo remociones de los estratos antiguos desde los niveles de época medieval.

De todos los cortes practicados, las obras que ahora nos importan corresponden a la cata 8 , la que hasta la fecha ha sido estudiada con mayor detenimiento (Belén y Escacena, e.p.).

\section{El Muro 5}

En la zona meridional de dicha cata, un muro fabricado a base de la alternancia de paños de mampostería con otros de sillería - al que se denominó muro nº 5-, servía de articulación a dos fases de construcción romanas. Esta última reutilización supone que en el siglo I d. C. la estructura original ya había caido en desuso. El Muro 5 discurre en una longitud de $10 \mathrm{mts}$. en sentido NW-SE, casi perpendicular a la muralla almoravide, y tiene $0,55 \mathrm{mts}$. de ancho. En el extremo norte ha sido cortado por remociones medievales; pero en el opuesto, la construcción continúa bajo la zona no excavada. Antes de perderse en el testigo, pudimos comprobar que el muro cambiaba de orientación y se prolongaba en sentido W-E (Lám. I, 1).

Su construcción combina paños de sillares tallados en caliza de cantera local, de 1,20 $\times$ $0,55 \times 0,55 \mathrm{mts}$., $\mathrm{y}$ aparejo de piedra irregular de tamaño medio. A veces los sillares constituyen auténticos pilares formados por superposición de hiladas de un único bloque colocado a soga (Fig. 2, Lám. II, 1), y otras se distribuyen de forma menos sistemática en hiladas de uno o dos sillares, a soga o a tizón (Fig. 2, Lám. III, 1). Además, el aparejo de mampostería se ha tratado de forma diferente según las caras. En la que mira hacia el borde oriental del tell, que suponemos la exterior, las piedras se superponen en seco (Fig. 2). La cara opuesta queda en gran parte oculta por las construcciones que se adosaron a la estructura en época romana, pero el único tramo visto corresponde a un paño de mampostería tratado de una forma mucho más cuidada; las piedras han sido retocadas para 

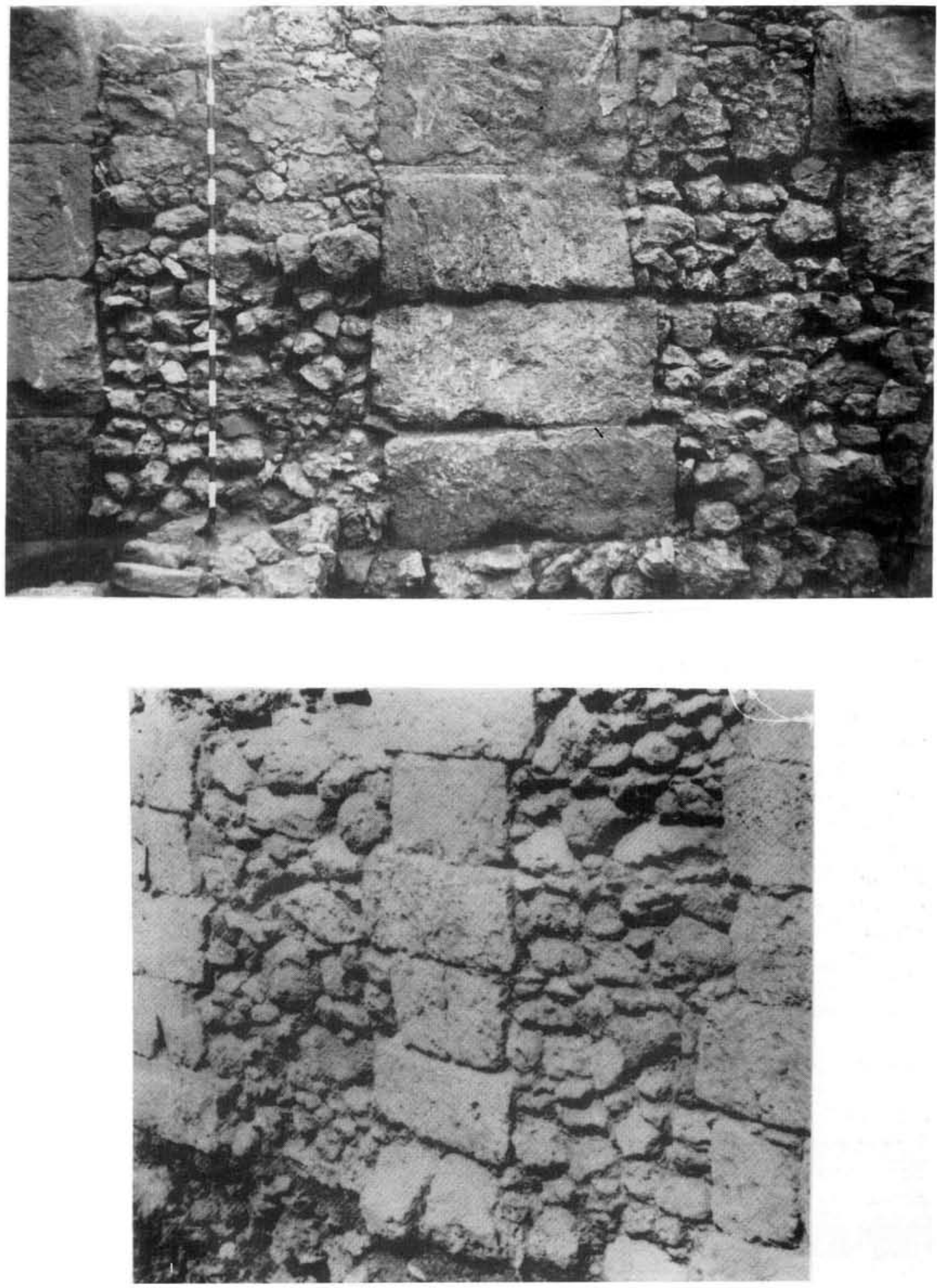

Lám. II. Niebla (Huelva). Cata 8. 1) Muro 5, detalle de la cara Este. 2) Muro de pilares de Tiro (Bikai, 1978: lám. LXXXIX. 5) 

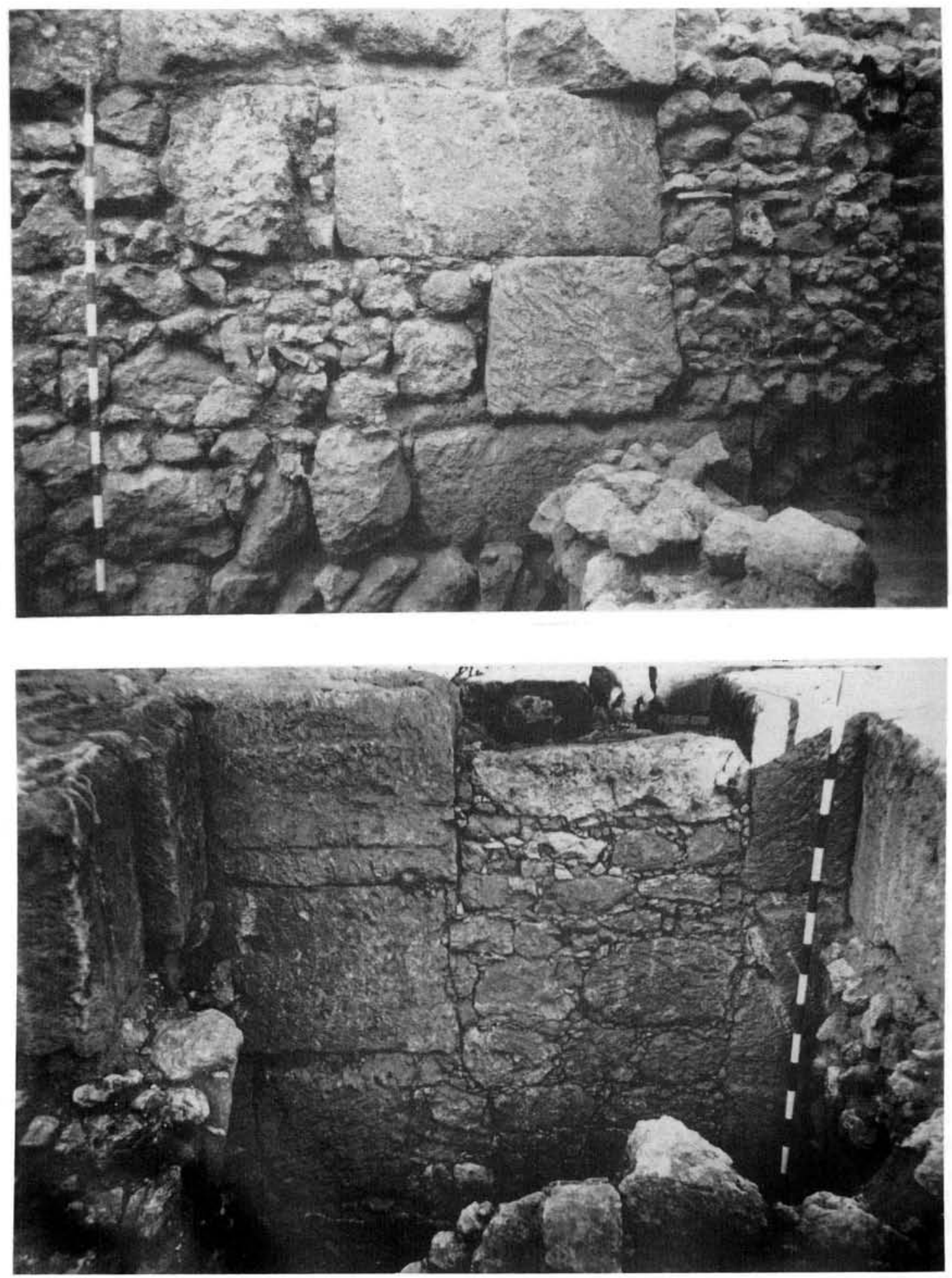

Lám. III. Niebla (Huelva). Cata 8. Muro 5. 1) Detalle de la cara Este. 2) Detalle de la cara Oeste.

T. P.. $\mathrm{n}^{2} 50,1993$ 
obtener una pared lisa y los huecos entre mampuestos se han rellenado minuciosamente con otras piedras irregulares de pequeño tamaño asentadas con barro. El resultado es una obra de gran solidez y aspecto cuidado (Lám. III, 2). En otras zonas del solar documentamos muros construidos en ambas caras con esta técnica, en tanto que el interior se rellena de piedras de menor tamaño (Belén y otros, 1983: 975; Belén, 1986: láms. I y II) (Láms. I, 2 y IV, 2).

Este muro 5, que aparentemente carece de zanja de cimentación, asienta de forma inmediata sobre construcciones anteriores de unos $70 \mathrm{cms}$. de anchura, que discurren paralelas entre sí en sentido E-O y, por tanto, perpendiculares a aquél. Los muros más antiguos, que corresponden a una misma habitación de $3 \times 4$ mts., fueron manipulados para adaptarlos a su nueva función de cimientos parciales de la estructura 5. La remodelación se observa con claridad en el caso del que llamamos muro $\mathrm{n}^{\text {o }}$ 18, ya que sobre él se encajó un sillar lo suficientemente bien acoplado como para producir la sensación de que fue esta estructura $\mathrm{n}^{\circ}$ 18 la que se adosó a la $\mathrm{n}^{\underline{0}} 5$, y no al revés. A mayor profundidad, la base del muro 5 apoya también sobre el $n^{\circ} 28$. La cimentación, ligeramente más ancha que el propio muro, llega a profundizar entre 0,90 y $1,10 \mathrm{mts}$., según las zonas (Fig. 2). Se inicia por encima de la hilada superior de los muros 18 y 21 , coincidiendo en algunos tramos con el primero de los sillares de cada pilar. A partir de aquí se levantan 4 hiladas de sillares con una altura de 2,30 mts.

\section{El muro 24}

Los muros 18 y 21, que proporcionan asiento al muro 5, corresponden a estructuras de habitación más antiguas pavimentadas con finas capas de tierra apisonada o con gravilla. El primero de ellos es una pared medianera entre dos estancias que quizá estuvieron en su día comunicadas. En relacion con la más meridional de las dos debe ponerse el muro no 24 , del que sólo se ha conservado un tramo de 1,50 mts. de longitud y 0,90 de altura, adosado a la pared oriental de la Cata 8 . No disponía de conexiones claras con otras estructuras. En un extremo, el muro había sido cortado por remociones romanas y medievales; en el opuesto, posiblemente hiciera esquina con el $n^{\circ} 21$, a través de un sector de este último desmontado después de su abandono. Sin embargo, las técnicas usadas en la fabricación de uno y otro son diferentes. El muro $\mathrm{n}^{\circ} 24$, que es el único que ahora nos importa por lo que se refiere a este conjunto, está levantado con piedras calizas de tamaño mediano cuya cara externa ha sido trabajada hasta conseguir una superficie plana y regular. Los huecos que quedan entre los distintos mampuestos se rellenaron sistemáticamente con otras piedrecillas mucho más pequeñas que, a modo de cuñas apretadamente, encajadas, contribuyen a dar cohesión, solidez y regularidad a la obra (Lám. IV, 1).

Por las razones expuestas no podemos establecer con precisión el contexto estratigráfico que se relaciona con el origen de esta estructura muraria, pero dado que la misma parece tener cierta relación estructural con el muro 21 , y éste a su vez con el 18 y con el 25 , se debió construir con toda probabilidad en una fecha comprendida entre los últimos moméntos de colmatación del nivel VII y los primeros del VI.

\section{CRONOLOGIA}

1. Por lo que se refiere a la época de utilización de estas construcciones, hay que señalar que los niveles II y III constituyen las acumulaciones estratigráficas correspondientes a la destrucción de los edificios romanos nacidos en torno al muro 5. En consecuencia, la cronología de ambas capas debe ser considerada también la del final de esa estructura $n^{\circ} 5$. Al oeste de la misma se había construído una habitación pavimentada con un mosaico cuya fecha debe llevarse a los siglos II y III d. C. aproximadamente. Al este en cambio, la estancia romana que había sido levantada en el nivel IV se destruye en la segunda mitad del siglo I de la Era.

Pero interesa más aquí analizar los datos que otorguen una cronología inicial para esta estructura. Las características de la estratigrafía obtenida en esta cuadrícula certifican que dicho muro se construyó a partir del nivel V, en el que se hallaron incluso los desechos de retocar in situ los sillares. A veces, la base de la obra llega hasta el nivel VII, pero esto debe ser considerado 
producto de la cimentación de la misma a más profunda cota en algún que otro punto, en función sobre todo de la búsqueda de un suelo firme donde asentarla.

La V es una potente capa de arcillas de color rojo acastañado, en parte compuesta por la destrucción de otras paredes de adobe anteriores superpuestas a los muros 18 y 21 , que, como hemos indicado, habían sido desmontadas para que sirvieran parcialmente de basamento al muro 5. Entre el barro salido de la destrucción de esos adobes se halló parte de un tronco quemado del que se pudieron obtener dos muestras radiocarbónicas, que suministraron las fechas de 150 y 140 a. C., una cronología parcialmente confirmada, como a continuación se verá, por los materiales cerámicos más modernos.

En realidad, la capa $V$ constituye un paquete de relleno y nivelación que explica la heterogeneidad cronológica de los tiestos hallados en él. Se encontraron fragmentos de recipientes cerámicos fabricados a mano, procedentes con toda seguridad de la remoción de sectores del hábitat más antiguo, y trozos de platos de la especie "gris de occidente", ambos conjuntos decorados a veces con retícula bruñida. A su vez, también la cerámica a torno pintada refleja esta mezcla de especies alfareras y de tipos de vasos con diversas dataciones. Pero los testimonios más recientes de este estrato aconsejan fecharlo a mediados del siglo II a. C. aproximadamente.

En efecto, entre los elementos más modernos destacan por su innegable personalidad los "platos de pescado" (Fig. 3: 1 y 2), que siguen prototipos griegos extendidos por el Mediterráneo sólo a partir de los siglos V y IV a. C., y que en la Península Ibérica aparecen cuando se hacen evidentes las influencias helénicas (Luzón, 1973: 34-35 y 56). La baja Andalucía ha proporcionado paralelos bien datados en el Pajar de Artillo (Luzón, 1973: 41-42), en Alhonoz (López Palomo, 1979: 78-79), en el Cabezo de San Pedro (Belén y otros, 1977: 179; FernándezMiranda, 1975: lám. 216) y en La Tiñosa entre otros sitios, con una datación de los siglos III y II a. C. (Belén y Fernández-Miranda, 1978: 218-234). Según la corrección de las fechas de Alhonoz propuesta por uno de nosotros (Escacena, 1987a: 275-279), a fines del siglo III o a

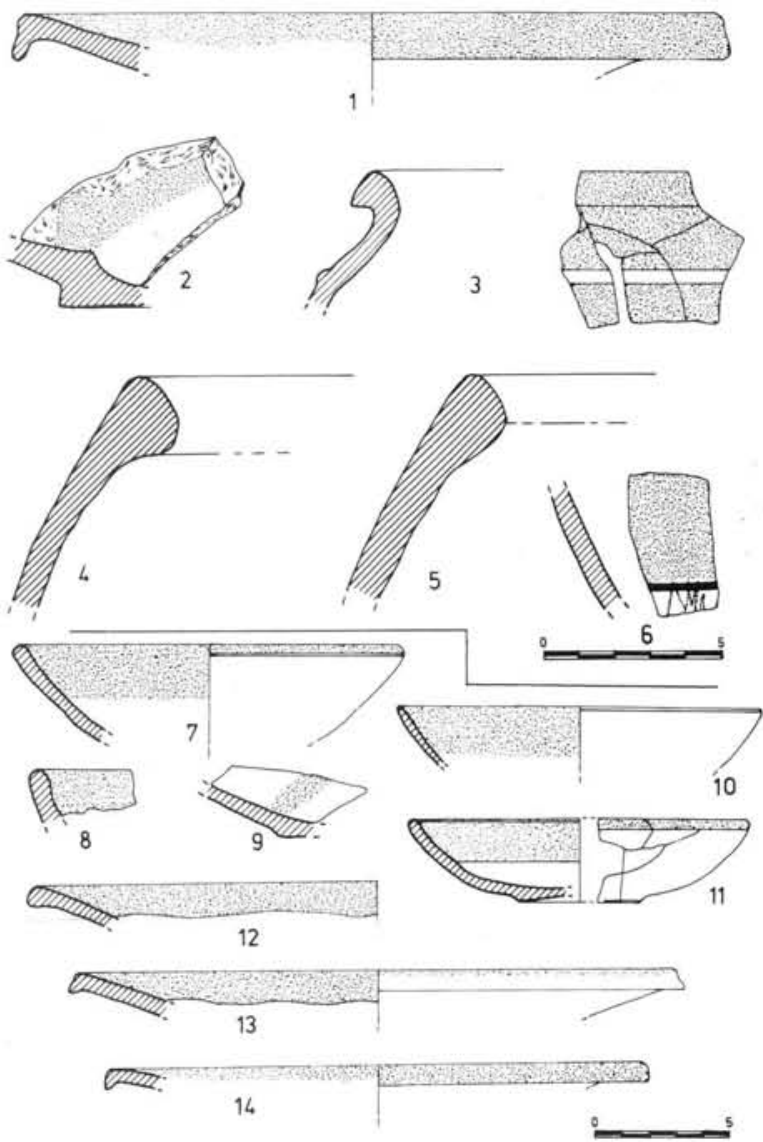

Fig. 3. Niebla (Huelva). Cata 8. Cerámica del Nivel Va (15) y VIa (6-14).

comienzos del II a. C. habría que datar allí el depósito de vasijas de la "Fase IV", que contenía recipientes de este tipo (López Palomo, 1979: fig. 9: 1-3, y 1981: fig. 24: 1-3). Desde mediados del siglo III a. C. están fechados los ejemplares del Macareno (Pellicer y otros, 1983: fig. 29: 1.785), mientras que en Itálica llegan hasta comienzos del I a. C. (Luzón, 1973: láms. X: E, XXXIX: E-F y LVII: G).

A partir del 500 a. C. se documentan en el Macareno los vasos con baquetón en el hombro (Fig. 3: 3), donde duran hasta el siglo III a. C. (Pellicer y otros, 1983: figs. 33: 1.670-1.671, 42: 1.380 y $53: 1.113-1.122$ ). La forma perduró en Andalucía occidental hasta el siglo I a. C. (Escacena, 1987b: 609-624).

Algunos fragmentos de ánforas procedentes de este contexto estratigráfico pertenecen a tipos que, en los casos más recientes (Fig. 3: 4 y 

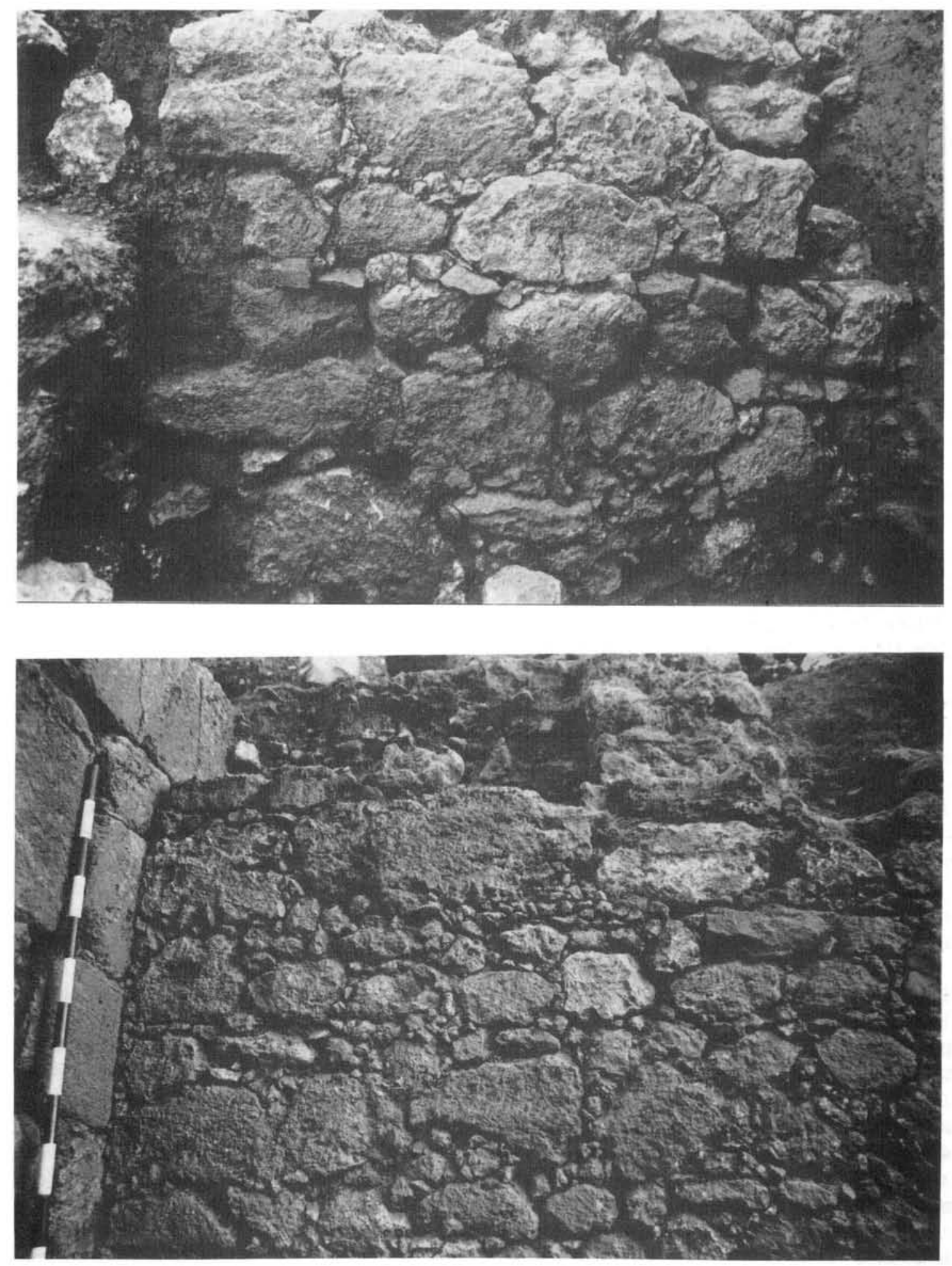

Lám. IV. Niebla (Huelva). 1) Cata 8. Muro 24. Cara Oeste. 2) Cata 4, muro construido con la misma técnica (excavaciones del Prof. R. de Balbín).

T. P.. $\mathrm{n}^{2} 50,1993$ 
5), se fechan en la segunda mitad del siglo III a. C. y en toda la centuria siguiente (Pellicer, 1978: fig. 7: 1.884 y 1.886; Muñoz, 1986: 476 y fig. 7: E-1).

De todos estos testimonios se deduce que, al menos en teoría, el nivel V podría corresponder tanto a la segunda mitad del siglo III como a casi todo el II a. C., de forma que la inclinación que hemos mostrado hacia la fecha más precisa suministrada por el C-14 se debe a que los niveles que cierran por arriba y por abajo esta capa estratigráfica restringen la datación de la misma a mediados del siglo II a. C. (Belén y Escacena, e.p.).

2. En cuanto al muro 24 , ya advertimos antes que puede ser contextualizado, sólo con relativa precisión, entre los niveles VI y VII, de manera que serían las fechas fronterizas entre ambas capas las que permitirían ofrecer una datación aproximada para dicha construcción.

Analizando la estratigrafía de arriba hacia abajo, según el proceso lógico de excavación, la capa VI debería centrarse en la segunda mitad del siglo III a. C. según la documentación que contiene. Además de algún fragmento de cerámica común, que analizamos más adelante, los que proporcionan mejor cronología pertenecen a dos conjuntos: vasos pintados de estilo turdetano y ánforas.

Dentro del primer lote destacan los cuencos en forma de casquete esférico (Fig. 3: 7-11), que se constatan en Andalucía occidental desde el siglo VII a. C. según acreditan el Cerro Salomón (Blanco y otros, 1969: 136:f, fig. 16), el Macareno (Pellicer y otros, 1983: 159, fig. 61: 906, 908 y 913) y Carmona (Bonsor, 1899: 124, fig. 163; Carriazo y Raddatz, 1960: 23, fig. 6: 1-5). Los paralelos más recientes para esta forma se han recuperado, con fecha relativamente precisa, en Itálica, donde llegan a mediados del siglo I a. C. (Luzón, 1973: 28 y 118, lám. LXII: K). Un segundo recipiente de cerámica pintada que aparece en este nivel es un plato de labio caido más o menos desarrollado (Fig. 3: 12-14). Los fragmentos de borde conservados son suficientes para reconocer la forma completa, que corresponde a la $\mathrm{n}^{\circ} 2$ de la clasificación llevada a cabo para los materiales de Mesas de Asta por Cuadrado (1962: fig. 4: 1-2). Por su origen y cronología, el tipo ha sido también llamado "plato iberopúnico" (Pellicer, 1982: fig. 21: 4 y 6). Se trata de un recipiente muy típico de Andalucía occidental (Escacena, 1987b: 240), donde comienza a mediados del siglo VI a. C. según el Cerro Macareno (Pellicer y otros, 1983: fig. 58: 998 y 1.002) y termina antes del cambio de Era según Alhonoz (López Palomo, 1981: fig. 9:8). Debemos señalar en tercer lugar, a pesar de la pequeñez del fragmento, la presencia en este estrato de un tema decorativo que se ha definido como "segmentos" o «sectores" de círculos concéntricos (Fig. 3: 6). Es un motivo que, por lo que se refiere a Andalucía y contando sólo con la documentación bien fechada, aparece por primera vez en Cástulo durante la primera mitad del siglo V a. C. (Blázquez, 1975: fig. 66: 20), extendiéndose más tarde hacia la depresión inferior del Guadalquivir y áreas periféricas, hasta llegar a Huelva a fines de dicha centuria (Belén y otros, 1977: figs. 54: 6, 58: 4 y 72: 5) y a La Tinosa a comienzos de la siguiente (Belén y Fernandez-Miranda, 1978: fig. 31: 8). En conjunto, y por lo que hoy sabemos, esta decoración pervivió al menos hasta el siglo I d. C. en todo el sur peninsular, porque existen exponentes con esta fecha tardía en Villaricos (Astruc, 1951: lám. XXVI: 2), en Córdoba (De Los Santos, 1955: láms. III: 3 y IV. García y Bellido, 1952: fig. 6) y en Cástulo (Blázquez, 1975: figs. 146: 2, 148: 1 y 154: 1; Blázquez, 1979: figs. 11: 21, 40: 753 bis y 45: 784; Blázquez y Fernández Uriel, 1974: fig. 8: 1). Si se tiene presente que tanto en la provincia de Huelva como en el Bajo Guadalquivir este tema ornamental de la cerámica afectó sobre todo a la vajilla de los siglos III y II a. C. (Escacena, 1987b: 978), su presencia en este estrato de Niebla sugeriría tal vez una datación de fines del siglo III a. C. o, como mucho, de comienzos del siguiente. Por último, el "plato de pescado" bícromo de este nivel (Fig. 4: 1) tiene sus paralelos más estrechos en el depósito cerámico de Alhonoz (López Palomo, 1979: fig. 9: 1-2), que debe fecharse, según hemos apuntado antes, a fines del siglo III o a comienzos del II a. C. aproximadamente.

En cuanto al segundo grupo, es decir, a las ánforas (Fig. 4: 2-5), puede relacionarse con piezas del estrato II de La Tiñosa (Belén y Fernández-Miranda, 1978: fig. 22: 2 y 4) y con ejemplares que en el Macareno se llevan a la segunda mitad del siglo III y a la primera del II 

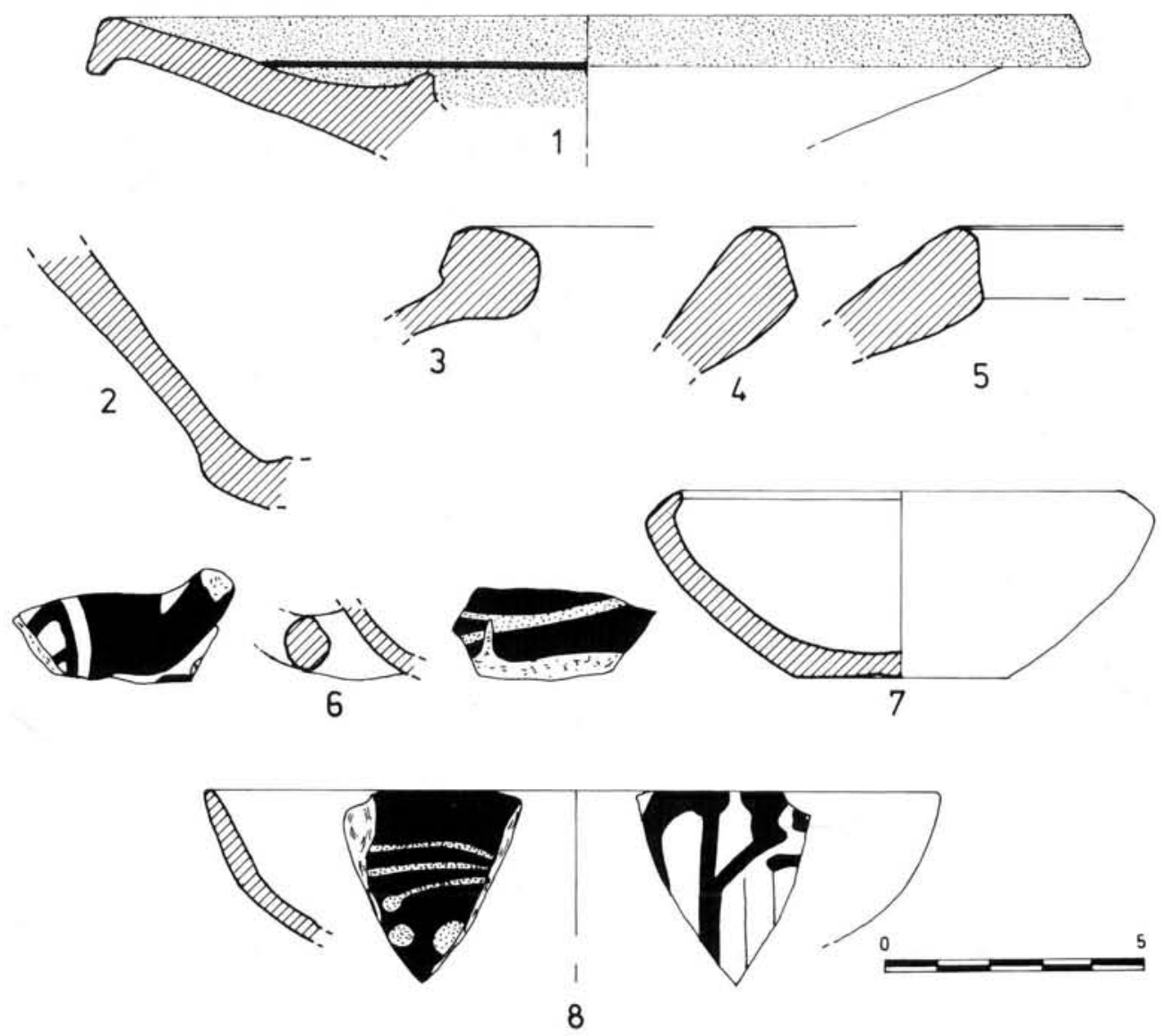

Fig. 4. Niebla (Huelva). Cata 8. Cerámica del Nivel VIa (2-3), VIb (1 y 4-6) y VII (7-8).

a. C. (Pellicer, 1978: 397 y figs. 7: 1.886 y 207, y 12: 2.010$)$

Un último testimonio de esta capa arroja cierta precisión cronológica, porque no se conocen paralelos para el pequeño cuenco-lucerna que lleva carena próxima al borde (Fig. 4: 7) con anterioridad a fines del siglo III a. C. (Escacena, 1987b: 354 y figs. 218-225).

La presencia de cerámica ática en el nivel VII es sin duda la circunstancia que más precisa la cronología de esta capa y de los materiales en ella contenidos. Son fragmentos de dos kylikes de figuras rojas (Fig. 4: 6 y 8) que tienen una fecha de la primera mitad del siglo IV a. C. De hecho, el repaso general de la cerámica turdetana de este nivel que a continuación abordamos no contradice en absoluto esta asignación cronológica.

Ya hemos comentado al estudiar los ejemplares del nivel VI que los cuencos en forma de casquete esférico (Fig. 5: 1-3) pueden tener perfecta cabida en este marco temporal. Lo mismo ocurre con el vaso de baquetón en el hombro (Fig. 5: 4), que en este caso muestra estrechos paralelismos, debido al perfil anguloso de dicha moldura, con la mayor parte de los ejemplares de Andalucía occidental, donde el tipo resulta especialmente abundante (Escacena, 1987b: 616). Otros materiales pintados arrojan poca luz al estudio cronológico de este nivel estratigráfico (Fig. 5: 5 y 7).

Las ánforas de esta capa (Fig. 5: 6) responden al tipo llamado "Carmona" por A. Rodero (1990: fig. 87:A), por ser característico de este yacimiento desde fines del siglo $\mathrm{V}$ y durante todo el IV a. C., y a las Mañá A, que en el Cerro Macareno se fechan a principios del siglo IV a. C. (Pellicer, 1978: 381 y fig. 5: 1.401).

En consecuencia, del análisis de toda esta documentación se deriva que, si el muro 24 


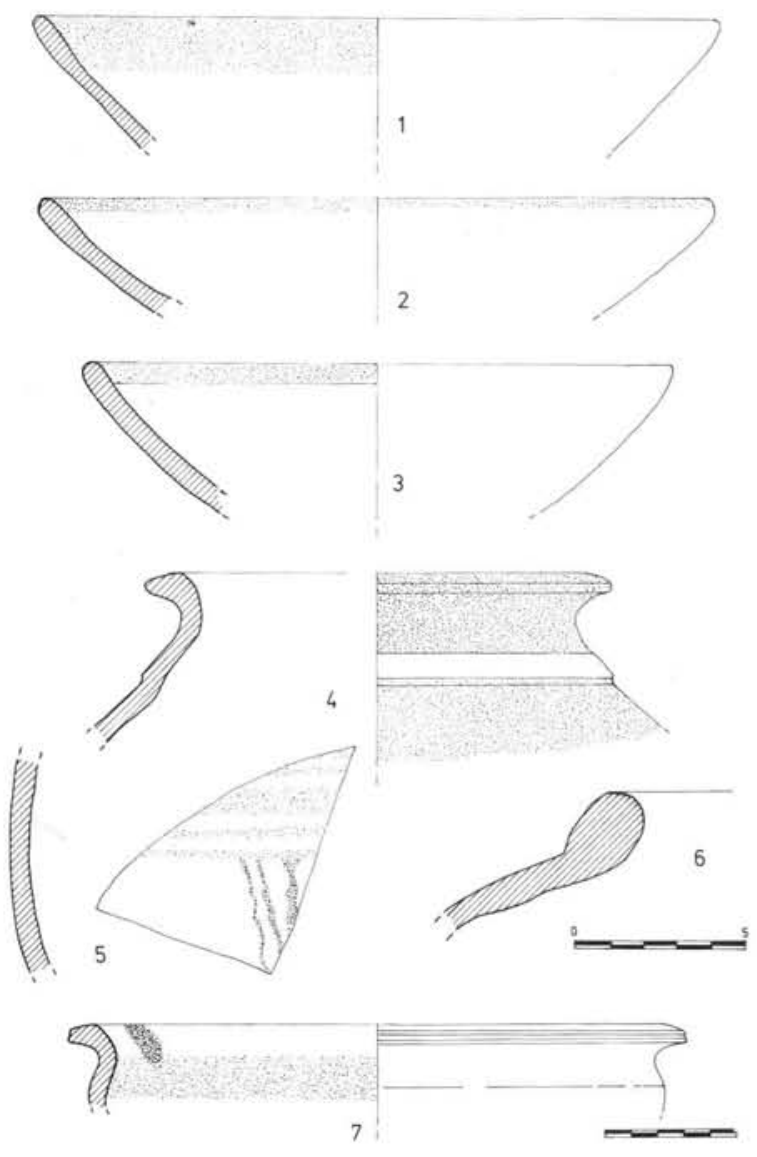

Fig. 5. Niebla (Huelva). Cata 8. Cerámica del Nivel VII.

puede situarse estratigráficamente entre los niveles VI y VII, podría haberse construido en una fecha en torno al 300 a. C. por citar una datación centrada entre las posibilidades extremas que ofrecen esas dos capas.

\section{LOS PARALELOS}

\section{El muro 5 y los muros de pilares}

La técnica de construcción del muro 5 como característica del mundo fenicio, se conoce bien desde la publicación del trabajo de J. Elayi (1980) sobre todo (cf. también Stern, 1977 y Sharon, 1987). Con múltiples variantes, el muro de pilares se utiliza en una amplia zona del Próximo Oriente (Elayi, 1980: 176) y en los territorios del Mediterráneo Central y Occidental en los que la presencia fenicia fue importante
(Elayi, 1980: 179). De unos años acá, las excavaciones arqueológicas han permitido documentar construcciones similares en el Bajo Guadalquivir y, en general, en el Suroeste de la Península Ibérica. Los ejemplos son de momento escasos y de cronología dispar. En la primera mitad del siglo VIII a. C. (Fernández Jurado, 1986-89: 170) se fecha el lienzo de muro que colmata una pequeña vaguada en el Cabezo de San Pedro de Huelva. Consta de un pilar con sillares de caliza, colocados en hiladas alternativas a soga y tizón, al cual se adosan dos paramentos de mampuestos de pizarra. En opinión de los excavadores, debió levantarse para contener las tierras del cerro, evitando que se desprendiesen sobre la zona de hábitat que ocupaba la ladera (Fernández Jurado, 1986-89: 170 ). Otros autores admiten también esta posibilidad, pero tampoco descartan que pudiera tratarse de un tramo del recinto defensivo que rodearía la parte más alta del cabezo de San Pedro (Fernández-Miranda, 1986: 236). Al margen del problema de su funcionalidad, la obra se ha interpretado como un regalo introductorio de mercado hecho por los fenicios para una comunidad local cuyas élites controlarían las ricas explotaciones mineras de la provincia (Fernández Jurado, 1988-89: 286).

En 1987 se documentó en un solar de la ciudad de Carmona (Sevilla) un tramo de $4 \mathrm{mts}$. de longitud de un muro de 1,10 mts. de ancho. Está construido con un pilar de sillares colocados a soga y tizón, intercalado con paños de mampostería. El muro presenta la particularidad de que los mampuestos han sido retocados hasta conseguir una cara plana, y calzados con piedras mas pequeñas; el resultado es una pared regular y de buena fábrica. Toda la piedra utilizada es calcarenita de cantera local. Esta estructura, para la que se supone función defensiva, se fecha en el siglo VI a. C. (Cardenete y otros, 1990: 261 y 263) y constituye, de momento, el ejemplo más antiguo del empleo combinado en una misma construcción de las dos técnicas descritas en relación con el muro 5 de Niebla. Sin ser idéntica, la estructura se aproxima a la que Elayi (1980: fig. 2a) incluye en su tipo B regular.

El análisis de las dimensiones de estos muros permite hacer algunas observaciones de interés. El de Niebla tiene 0,55 mts. de ancho. 
Jodin (1975: 43, 44 y 68-69) ha comprobado que en los edificios prerromanos de ciudades como Mogador o Volubilis, se repiten con mucha frecuencia los muros de 0,55 mts. de ancho. En su opinión, esta medida es la del codo real de los caldeos, que los fenicios hicieron suyo y difundieron en sus colonias occidentales (2). Los ejemplos que el autor documenta en Marruecos están fechados entre el siglo III a. C. y mediados del I d. C. (Jodin, 1975: 73). La anchura del muro de Carmona es exactamente el doble $(1,10 \mathrm{mts}$.) y de los sillares utilizados en su construcción, uno responde también a la misma unidad de medida, pues tiene 0,56 mts. de anchura y 1,38 de longitud, que equivale a 2,5 veces 0,55 (Cardenete y otros, 1990) (3).

Los sillares del muro de San Pedro en Huelva tienen $1,1,15$ y $1,20 \mathrm{mts}$. de longitud; 0,50 de ancho y $0,37,0,47$ y $0,45 \mathrm{mts}$. de altura (Ruiz Mata y otros, 1981: 184). El gran muro de Toscanos construído en época imperial romana, pero con materiales supuestamente reutilizados de edificios más antiguos (Niemeyer, 1982: 103106), está hecho con bloques tallados de alturas comprendidas entre 0,45 y $0,48 \mathrm{mts}$. (Lindemann y otros, 1972: 129) (4). La coincidencia de una medida en torno a $0,46 \mathrm{mts}$. podría sugerir que se ha utilizado en estos casos una misma unidad. En el urbanismo más antiguo de Volubilis está bien documentado el empleo de un módulo de $0,46 \mathrm{mts}$, que se utiliza sobre todo en elementos de columnas (Jodin, 1975: 73), es decir, en estructuras de desarrollo vertical. No sería de extrañar que la altura de los bloques de las construcciones que estamos mencionando se rigiera por el mismo sistema metrológico (5).

Querríamos aludir, por último, a la gran pervivencia del muro de pilares en el sur de la

(2) El autor distingue en el sistema metrológico de las ciudades púnicas de Marruecos un codo chico de 0,46 metros y un codo grande de 0,55 metros.

(3) Sólo se han podido medir tres de estos sillares cuyas dimensiones son $138 \times 56 \times 40,106 \times 64 \times 40$ y 112 $\times 60 \times$ ?

(4) La longitud de estos mismos sillares oscila entre 0,90 y $1,04 \mathrm{mts}$. y la anchura o profundidad entre 0,37 y $0,60 \mathrm{mts}$.

(5) Aunque nos hemos referido sólo a las construcciones de sillares, queremos anotar que la utilización de estos patrones de medidas es más amplia. Sirva de ejemplo la mención de los muros de Chorreras con grosores que van de 0,45 a 0,55 mts.: Aubet y otros. 1979,99 .
Península Ibérica. En la propia Niebla, M. del Amo documentó una fase de construcción de época romana imperial con edificaciones hechas de forma similar; la única diferencia está en que los tramos son mas cortos, los pilares se forman por la superposición de un único sillar cuadrado y los espacios entre pilares son muy regulares (6). En Carmona se conocen también muros construidos en el siglo I d. C. con pilares de un único sillar por hilada, de entre 58 y $60 \mathrm{cms}$. de lado (Cardenete y otros, 1991: 563-564). Otros ejemplos igualmente de época romana se conocen en los yacimientos de Peñaflor (Keay, 1991: 281, lám. 2) y de Cerro del Mar (7). Aunque en las colonias fenicias de la costa de Málaga no se ha documentado hasta el momento el empleo de muros de pilares, el último de los ejemplos citados permite suponer que esta tradición constructiva se conocía ya con anterioridad en la zona, si no desde los tiempos fundacionales, si por las fechas en que estas técnicas alcanzan mayor difusión, que en el sur de la Península Ibérica, como en el resto del Mediterráneo y en Oriente (Elayi, 1980: 180), es a partir del siglo VI a. C. El mismo fenómeno de pervivencia de un tipo de construcción emparentado con el muro de pilares de tradición fenicia, se conoce en la arquitectura del Norte de Africa durante la época romana (Elayi, 1980: 179).

\section{La técnica constructiva del muro $\mathbf{2 4}$}

Hasta hace poco no se conocían conjuntos arquitectónicos importantes que permitieran apreciar que la técnica con que se ejecutó el muro 24 , y el paño visto de la cara occidental del muro 5, no podía entenderse como un simple recurso de albañilería encaminado a conseguir una fábrica más sólida, sino que el resultado final es consecuencia del conocimiento de unas tradiciones constructivas bien definidas. Hoy sabemos que el origen de estas tradiciones hay que buscarlo en el Próximo Oriente, y que su implantación en el extremo más occidental del Mediterráneo está relacionado, como sucede

(6) Excavaciones todavía en estudio.

(7) Según información que agradecemos de profesor Oswaldo Arteaga, los muros de esta factura se fechan en el yacimiento de Cerro del Mar entre la segunda mitad del siglo II a. C. y mediados del I d. C. 
con los muros de pilares, con la colonización fenicia. En ese ámbito pueden encontrarse los mejores paralelos para los muros de Niebla (8). Tell Abu Hawam (Hamilton, 1933: lám. XXI,1), Hazor (Yadin y otros, 1961: lám. CXXXVI,1) o Tell El-Far'ah (Chambon, 1984: 29, fig. 6a y láms. 24, 29a y 34a), nos ilustran sobre el uso de paramentos de mampostería regular calzada con piedras pequeñas tanto en construcciones civiles como militares. En Mozia, un paño intercalado entre pilares monolíticos fechado en un momento antiguo del siglo VI a. C. documenta la utilización de este tipo de mampostería en las colonias del Mediterráneo Central (Ciasca, 1986: 226 y fig. 57). En Andalucía, los ejemplos mas claros de que por las mismas fechas se habían ya construído algunas obras con esa fábrica están en Carmona. En 1980, un equipo de la Universidad de Sevilla dirigido por el profesor M. Pellicer realizó excavaciones junto al sondeo practicado a fines de los años cincuenta por Carriazo y Raddatz (1960), en el lugar conocido como Raso de Santa Ana. En estos trabajos se documentó un muro para el que se calculó un ancho de $0,80 \mathrm{mts}$. y que se conservaba en una altura de casi $3 \mathrm{mts}$. En su construcción se utilizaron piedras de calcarenita local «(...) colocadas horizontalmente, aunque en ocasiones preparadas, no están escuadradas, oscilando sus ejes entre 0,15 y $0,40 \mathrm{mts}$ " (Pellicer y Amores, 1985: 72, láms. I,2 y II,1). Las ilustraciones permiten comprobar que la preparación a que se refieren los autores ha consistido en retocar la cara externa de las piedras para conseguir una superficie plana y regular; asimismo, puede observarse que los mampuestos están calzados con piedra más pequeña y que su cimentación es algo más ancha que el propio muro y de factura más grosera. La construcción se ha fechado en los primeros años del siglo VI a. C. (Pellicer y Amores, 1985: 72 y fig. 12). También pudimos reconocer personalmente un muro hecho con idéntica técnica en otro solar próximo excavado en 1987 (Gil de los Reyes y

(8) A la hora de buscar paralelos, hemos tenido más en cuenta el aspecto general de la obra que los detalles, pues la solución de calzar piedras con guijarros es tan elemental que, atendiendo sólo a este hecho y no al resultado, podríamos encontrar ejemplos en cualquier sitio y en cualquier época. otros, 1990) (9), situado en la misma plaza y vecino de aquel otro en que se halló el tantas veces ya citado muro de pilares cuyos tramos de mampostería también se construyeron de la misma forma. Pero sin ninguna duda el mejor ejemplo lo tenemos en el Castillo de Doña Blanca, un poblado fenicio fundado a principios del siglo VIII a. C. en las proximidades de Gadir (Ruiz Mata, 1988: 41). A lo largo del siglo IV a. C., se produce en el asentamiento una reordenación urbanística que supone también la implantación de técnicas de construcción que no se emplean en el lugar durante la fase más antigua. Estas técnicas, que siguen en uso hasta el final del poblado en los últimos años del siglo III a. C., son las mismas que documentamos en Niebla, y los edificios de ambos yacimientos son tan parecidos, que resulta inevitable suponerlos resultado de los mismos estímulos. Aunque la documentación que poseemos para este último es mucho más escasa, comprobamos que en los dos poblados se construyen de idéntica forma las murallas, los almacenes y las casas (cf. Ruiz Mata, 1987: 364) (10). Por último, creemos encontrar similitudes entre los ejemplos mencionados y los restos de una casa del siglo III a. C. del poblado del Cerro Macareno (Pellicer y otros, 1983: 58 y lám. II, 1). Niebla probaría la perduración de esta tradición constructiva hasta mediados del II a. C.

\section{RECAPITULACION}

El trabajo que hemos presentado no pasa de ser una aportación modesta a la investigación de la influencia fenicia sobre la arquitectura prerromana en Andalucía occidental. Pero el ejemplo de Niebla plantea problemas importan-

(9) De estas excavaciones se ha ofrecido un breve informe en el que no tenía cabida la descripción pormenorizada de las distintas estructuras de construcción, pero pensamos que el muro que vimos en nuestra visita a la excavación debe ser el que las autoras llaman 3/A, que fechan entre "el último cuarto del siglo VI y la primera mitad del V a.C" y describen, precisamente, con las mismas palabras que utilizan Pellicer y Amores para referirse al hallado en el corte CA-80/A (Cf. Gil de los Reyes y otros, 1990: 583 con Pellicer y Amores, 1985: 72).

(10) La técnica de construcción que analizamos está mejor representada en otros sondeos del solar de la Puerta de Sevilla, cuyas excavaciones dirigió R. de Balbín. Estos trabajos están todavia pendientes de estudio y por ello desconocemos en qué momento de la vida de la ciudad se erigieron estas edificaciones. 
tes relacionados con el tiempo durante el cual se ejercen esas influencias y con el supuesto proceso aculturador que resulta del contacto entre extranjeros y poblaciones autóctonas.

En primer lugar cabe preguntarse cuándo se produjo la introducción de los conocimientos técnicos que implica la fabricación de paredes como las que hemos analizado.

Para el muro de pilares conocemos precedentes fechados en el siglo VIII a. C. en Huelva y en el siglo VI a. C. en Carmona. Estos ejemplos más antiguos permitirían suponer que a lo largo de unos 500 años se habrían ido transmitiendo los conocimientos que asegurarían la perduración de esta tradición constructora en Andalucía occidental.

Distinto es el caso de las obras de mampostería regular como el muro 24. Aunque es una técnica bien conocida en las ciudades del Próximo Oriente, no encontramos en la bibliografía temática de la Península Ibérica referencias al hallazgo de muros de construcción similar fechados durante el Período Orientalizante, aunque, en nuestra opinión, existen ejemplos inequívocos en Carmona, datados desde los primeros años del siglo VI a. C. Podría suceder que la ausencia de documentación no fuera real, y que, existiendo ejemplos, hubieran pasado desapercibidos por no resaltarse en la descripción los rasgos que caracterizan a los muros así construidos de cualquier otra obra que recurra también al empleo de ripios para calzar los mampuestos. Quizá en algún caso, la escasa entidad de los restos conservados haya impedido identificar el tipo de fábrica a que nos referimos, puesto que en muchas ocasiones de las estructuras originarias no encontramos más que la cimentación, y esta parte de la construcción hemos comprobado que se trata de forma mucho menos cuidada que las paredes. Pero parece significativo que en un asentamiento fenicio como el Castillo de Doña Blanca (Ruiz Mata, 1988: 41), esta forma de levantar los edificios aparezca como novedad con la remodelación urbanística de la última fase del poblado fechada durante los siglos IV-III a. C., y no antes (11). Sorprende asimismo la gran unificación de las técnicas de construcción

(11) En cualquier caso, habrá que esperar a la publicación de la sintesis que sobre las distintas campañas de excavación prepara actualmente el profesor Ruiz Mata, para saber en qué momento preciso se implantan estas técnicas en el poblado. a lo largo de toda la etapa, pues, como ya se ha comentado, las casas, los almacenes o las murallas de la ciudad fueron construidos de idéntico modo. La misma fábrica presentan las edificaciones del poblado que se funda en la primera mitad del siglo IV a. C. sobre la vecina Sierra de San Cristóbal, dominando el amplio estuario del Guadalete (12), y, como acabamos de indicar, también en los poblados del Bajo Guadalquivir creemos poder rastrear esta tradición constructiva hasta el siglo III a. C. (Pellicer y otros, 1983: 58 y lam. II, 1).

De momento, la documentación que poseemos es escasa, pero no podemos pasar por alto la coincidencia entre los datos que hemos comentado y el proceso de implantación de las técnicas de construcción fenicia en los territorios orientales y en las colonias del Mediterráneo Central. En el caso de los muros de pilares, los mejor estudiados, sabemos que, aún siendo conocidos desde fines de la Edad del Bronce, primero en las ciudades sirias del norte y después en las fenicias, progresivamente también en Palestina (Braemer, 1982: 120 y 140), el apogeo de su uso se produce entre los siglos VI-III a. C., y sobre todo durante el V-IV a. C.; ésta es también la época de su mayor difusión en los territorios coloniales (Elayi, 1980: 176 y 180). El muro onubense del Cabezo de San Pedro, de cronología próxima al de Tiro (Bikai, 1978: 10, 11, 67 y lam. LXXXIX, 5 y 6) (Lám. II, 2), representa sin duda el ejemplo más antiguo para esta tradición constructiva en el Mediterráneo Occidental, pero hoy por hoy constituye la excepción a la regla.

Posiblemente, la implantación de los paramentos mixtos de sillares y mampuestos sea sólo la manifestación más clara e identificable por ahora de un proceso más amplio de difusión de esquemas arquitectónicos y tradiciones constructivas de origen oriental, que explicaría la introducción por las fechas citadas en las tierras del sur de la Península de otros modelos de urbanismo y formas de edificar novedosas. Problema diferente y de mayor complejidad es explicar cómo se produjo el proceso de implantación de todos estos conocimientos en nuestra región.

Hasta hace pocos años se sostenía que la

(12) Agradecemos la información al profesor D. Ruiz Mata, director de las excavaciones que se llevan a cabo en ambos yacimientos. 
relación comercial con los fenicios había provocado tal grado de aculturación en los indígenas del Valle del Guadalquivir y del Suroeste, que sin ser fenicios podrían parecerlo. Más recientemente se han ido flexibilizando las posiciones iniciales y, junto al modelo tradicional, se ofrecen ahora otras alternativas de interpretación del fenómeno colonial que permiten abordar con esquemas menos rígidos los problemas de interacción cultural en las dos comunidades (González Wagner, 1986: 144 y ss.).

Estos otros modelos que defienden formas de contacto directo e, incluso, una estrecha vecindad entre comunidades orientales y autóctonos en las tierras de Andalucía occidental (González Wagner, 1986: 150-152), permiten explicar con más coherencia el proceso de aculturación, pero, a la vez, obligan a reflexionar sobre cómo se detecta en el registro arqueológico la presencia de esas comunidades de origen oriental establecidas en los centros minerometalúrgicos de la región de Huelva o en las fértiles tierras de la región de Carmona (González Wagner, 1986: 151). Porque, de aceptar tales supuestos téoricos, habría que suponer que al menos algunos de los rasgos que los investigadores hemos interpretado como pruebas de una profunda aculturación de las comunidades autoctonas, podrían ser las manifestaciones de la presencia estable de esas comunidades foráneas. En coherencia con su propia hipótesis, González Wagner (1986: 146-147) interpreta la Cruz del Negro (Carmona) como un cementerio de agricultores orientales.

En el caso que nos ocupa, el contacto directo y prolongado entre las dos comunidades explicaría de forma menos forzada la existencia de técnicas de construcción de tan clara tradición fenicia en los yacimientos que hemos examinado del área de Huelva y de Carmona. En otras ocasiones (Belén, 1986: 274), ya nos mostramos poco partidarios de sostener que el contacto esporádico con grupos de comerciantes extranjeros consiguiera cambiar las tradiciones arquitectónicas de la población local. Las influencias en aspectos arquitectónicos dicen otros autores (13) implican la llegada de grupos de pobla-

(13) A propósito del muro de San Pedro (Huelva) precisamente P. Leriche puntualiza a P. Rouillard que «(...) no se puede hablar de influencia en materia de arquitectura sin que esto implique la llegada de nuevas poblaciones que imponen su modo de construcción o de equipos técnicos" (Leriche y Tréziny (eds.), 1986: 422). ción o al menos, de técnicos. Ahora bien, en la línea iniciada por Gonzalez Wagner, si aceptamos que hay fenicios conviviendo en los mismos núcleos de población con los autóctonos, consideramos prioritario el problema de identificar a los habitantes de una casa o de un poblado de corte fenicio y discutir después, si procede, cómo una familia local, o toda una comunidad cambió sus costumbres y llegó a vivir de forma tan parecida a la de un fenicio. En estos momentos nos inquieta pensar que, en la investigación de la influencia fenicia en Andalucía occidental, como se dice en nuestra tierra, hayamos comenzado a construir la casa por el tejado.

\section{BIBLIOGRAFIA}

Almagro Gorbea, M., Dominguez de la Concha, A. y LÓPez-Ambite, F. (1990): “Cancho Roano. Un palacio orientalizante en la Peninsula Ibérica", Madrider Mitteilungen, 31: 251-308.

Astruc, M. (1951): La Necrópolis de Villaricos (I.M.C.G.E.A. 25). Madrid.

AUBET, M. ${ }^{2}$ E. (1986): "Los fenicios en España: Estado de la cuestión y perspectivas". En G. DEL OLMo y M. ${ }^{a}$ E. Aubet (eds.): "Los Fenicios en la Península Ibérica", I: 938. Sabadell, Ed. Ausa.

Aubet, M. a E., MaAs-Lindemann, G. y Schubart, H. (1979): "Chorreras. Un establecimiento fenicio al Este de la desembocadura del Algarrobo". Noticiario Arqueológico Hispánico, 6: 91-138.

BELÉN, M. (1986): "Importaciones fenicias en Andalucía occidental». En G. DEL Olmo y M. ${ }^{a}$ E. AUBET (eds.): "Los Fenicios en la Península Ibérica", II: 263-278. Ed. Ausa. Sabadell.

BelÉN, M. y EsCACEnA, J. L. (1992): «Las comunidades prerromanas de Andalucía occidental». En M. AlmagroGorbea y G. Ruiz Zapatero (eds.): "Paleoetnología de la Península Ibérica». Complutum, 2-3: 65-87. Madrid.

- e.p.: «Niebla (Huelva). Excavaciones junto a la Puerta de Sevilla (1978-1982). La Cata 8”. Huelva Arqueológica, XII (1992).

Belén, M. y Fernández-Miranda, M. 1978: «La Tĩ̃osa (Lepe, Huelva)". Huelva Arqueológica, IV: 197-297.

Belén, M., Fernández-Miranda, M. y Garrido, J. P. (1977): "Los origenes de Huelva. Excavaciones en los Cabezos de San Pedro y La Esperanza». Huelva Arqueológica, III.

BELÉN, M. y otros (1983): «Excavaciones en Niebla (Huelva)". XVI C.N.A. Cartagena, 1982. Zaragoza: 971-982.

BENDALA, M. (1989) "La génesis de la estructura urbana en la España Antigua". Cuadernos de Prehistoria y Arqueología. Universidad Autónoma de Madrid, 16: 127-147.

- 1990: "Tartessos hoy a la luz de los datos arqueológicos y literarios". En "La Cultura Tartésica y Extremadura": 11-27. Mérida. 
BIKaI, P. M. (1978): "The Pottery of Tyre». Aris and Phillips Ltd. Warminster.

Blanco, A. y Luzón, J. M. (1975): "Resultados de las excavaciones del primitivo poblado de Río Tinto». En "Huelva. Prehistoria y Antigüedad": 235-247. Madrid.

BLANCO, A. y ROTHENBERG, B. (1981): "Exploración Arqueometalúrgica de Huelva». Ed. Labor, S.A. Barcelona.

Blanco, A. Luzón, J. M. a y Ruiz Mata, D. (1969): "Panorama tartésico en Andalucía oriental", En Tartessos y sus Problemas (V. S.I.P.P). Jerez 1968: 119-162. Barcelona.

BLÁZquez, J. M. (1975): Cástulo I. A.A.H., 8. Madrid.

- (1979): Cástulo II. E.A.E., 105. Madrid.

- (1991): «Panorama general del desarrollo histórico de la cultura tartésica desde finales de la Edad del Bronce, s. VIII a.C. hasta los orígenes de las culturas turdetana e ibérica. Los influjos fenicios". RSF, XIX, 1: 33-48.

BlázQuez, J. M. y FernáNDEZ URIEL, P. (1974): «Urna oretana en la muralla de Cástulo». Zephyrus, XXV: 343350.

Bonsor, G. (1899): “Les colonies agricoles pré-romaines de la vallée du Bétis». París.

BORJA, F. (1989): «Llanuras aluviales y terrazas holocenas del SW. de Andalucía: medios naturales y secuencias cronosedimentarias». En El Cuaternario en Andalucía Occidental: 155-170. AEQUA monografías 1. Sevilla.

BRAEMER, F. (1982): L'Architecture domestique du Levant a l'Age du Fer. Protohistoire du Levant. Ed. Recherches sur les civilisations, cahier $\mathrm{n}^{2} 8$. Paris.

CARDENETE, R. y LiNeRos, R. (1990): «Excavaciones arqueológicas practicadas en el solar $\mathrm{n}^{2} 2 \mathrm{c} /$ Barbacana Alta. Carmona. Sevilla”. Anuario Arqueológico de Andalucia/1988, III: 264-270. Sevilla.

CARDENETE, R. y otros. (1991): «Excavaciones arqueológicas de urgencia en el solar de la c/Higueral 2, Carmona (Sevilla)». Anuario Arqueológico de Andalucía/1988, III: 257-263. Sevilla.

CARDENETE R, y otros. (1991): «Excavaciones arqueológicas de urgencia en el solar de la $\mathrm{C} / \mathrm{Costanilla}$ Torre del Oro s/nº. Carmona (Sevilla)". Anuario Arqueológico de Andalucia/1989, III: 563-574. Sevilla.

CARO, R. (1634): “Antigüedades, y Principado de la Ilustrissima Ciudad de Sevilla. Y Chographia de su Convento Iuridico, o Antigua Chancilleria". Sevilla.

CARRIAZo J. de M. y RADDATZ, K. (1960): «Primicias de un corte estratigráfico en Carmona". Archivo Hispalense, 2. ${ }^{\mathrm{a}}$ época, $\mathrm{n}^{\mathrm{O}} 103-104$.

Celestino, S. (1991): «Cancho Roano, un complejo urbano orientalizante en Zalamea de la Serena (Badajoz)». En J. REMESAL y O. Musso (coords.): "La presencia de material etrusco en la Península Ibérica». Public. Univer. Barcelona: $439-455$.

Cerdeño, M. L. (1981): "Los broches de cinturón tartésicos". Huelva Arqueológica, V: 31-56.

Ciasca, A. (1986): "Fortificazioni di Mozia (Sicilia). Dati technici e proposta preliminare de periodizzazione». En P. LeRICHE y H. TRÉZINY (eds.): La Fortification dans l'histoire du Monde Grec. CNRS Colloque Intern. 614. Déc. 1982. París, CNRS, 1986: 221-227.

CUADRADO, E. (1956): «Los recipientes rituales metálicos llamados "braserillos" púnicos". Archivo Español de Arqueología, XXIX: 52-82.

- (1962): "Cerámica astitana de barniz rojo". VII C.N.A.: 385-408. Zaragoza.
Chambon, A. (1984): Tell El-Far'ah 1. L'Age du Fer. París, Eds. Recherches sur les Civilisations (Mémoire $\mathrm{n}^{\circ} 31$ ). París.

De Los Santos, S. (1955): Memoria de las Excavaciones del Plan Nacional realizadas en Córdoba (1948-50). Madrid.

Del AMO, M. (1975): «Enterramientos en cista de la provincia de Huelva». En "Huelva. Prehistoria y Antigüedad": 109-182. Editora Nacional. Madrid.

DElgado, A. (1891): «Bosquejo histórico de Niebla». Boletín de la Real Academia de la Historia, XVIII: 484-551.

Droop, J. P. (1925): «Excavations at Niebla in the province of Huelva, Spain". Annals of Archaeology and Anthropo$\log y$, XII, 3-4: 175-206.

ELAYI, J. (1980): «Remarques sur un type de mur phénicien». $R S F$, VIII.2: $165-180$.

ESCACENA, J. L. (1987a): «El poblamiento ibérico en el Bajo Guadalquivir". Iberos. Actas de las I Jornadas sobre el Mundo Ibérico/Jaen. 1985: 273-298. Jaén.

- (1987b): “Cerámicas a torno pintadas andaluzas de la segunda Edad del Hierro". Edición en microfichas. Cádiz.

EsCACENA, J. L. y BelÉN, M. (1991): «Sobre la cronología del horizonte fundacional de los asentamientos tartésicos". Cuadernos del Suroeste, 2: 9-42. Huelva.

FERNÁNDEZ JURADO, J. (1986): «Economía tartésica: minería y metalurgia". En "Huelva en su Historia. Miscelánea Histórica»: 149-170. Sevilla.

- (1988-1989): Tartessos y Huelva. Huelva Arqueológica X$X I, 1$. Huelva.

- 1991: "Influencia fenicia en la arquitectura tartéssica". Actas Jornadas de Arqueología fenicio-púnica I-IV (Ibiza 1986-89): 169-173. Trabajos del Museo Arqueológico de Ibiza. 24.

FERnÁNDEZ-Miranda, M. (1975): «El Cabezo de El Castillo o de San Pedro y problemas del poblamiento de la actual ciudad de Huelva durante el primer milenio. Avance de su estudion. En Huelva. Prehistoria y Antigüedadn: 221-234. Madrid.

- (1986): «Huelva, ciudad de los tartesios». En G. DEL Olmo y M." E. Aubet (eds.): "Los Fenicios en la Península Ibérica", II: 227-261. Ed. Ausa. Sabadell.

FORTEA, J. (1986): «El Paleolítico Superior y Epipaleolítico en Andalucía. Estado de la cuestión cincuenta años después». En Homenaje a Luis Siret (1934-1984): 67-78. Sevilla.

García y Bellido, A. (1952): "Nuevos datos sobre la cronología final de la cerámica ibérica y sobre su expansión peninsular». Archivo Español de Arqueología, XXV: 39-45.

- (1956): «Materiales de Arqueología hispano-púnica. Jarros de bronce». Archivo Español de Arqueología XXIX, 85-104.

- (1960): "Inventario de los jarros púnico-tartesios". Archivo Español de Arqueología, XXXIX: 44-63.

Garrido, J. P. (1971): La Prehistoria de Huelva. Madrid.

GARRIDO, J. P. y ORTA, E. M. (1967): Excavaciones en Niebla (Huelva). El "tholos" de "El Moro". Excavaciones Arqueológicas en España, 57. Madrid.

- (1975a): «Historia de la investigación arqueológica de la provincia de Huelva». En Huelva. Prehistoria y Antigüedad: 13-26. Editora Nacional. Madrid.

- (1975b): «El problema de Tartessos: una interpretación arqueológica”. En Huelva. Prehistoria y Antigüedad: 249-263. Madrid. 
GIL de los Reyes, M.a S., Gómez SAucedo, M.a T., y Rodriguez, I. (1990): "Carmona protohistórica, (Sevilla): Intervención en la Plazuela del Higueral $n^{2} 3 n$. Anuario Arqueológico de Andalucia/1987, III: 581-585.

GonzÁlez PRATS, A. (1983): Estudio arqueológico del poblamiento antiguo de la Sierra de Crevillente (Alicante). Anejo I de la Reva Lucentum, Universidad de Alicante.

GONZÁlez WAGNER, C. (1986): «Notas en torno a la aculturación en Tartessos». Gerion, 4: 129-160. Ed. de la Universidad Complutense, Madrid.

Hamilton, R. W. (1933): "Tell Abu Hawam. Interim report». The Quarterly of the Department Of Antiquities in Palestine, III/2: 74-80.

JODIN, A. (1975): "Recherches sur la metrologie du Maroc Punique et Hellénistique». Ed. Marocaines et Internationales. Tánger.

JuRADO, C. (1934): Mosaico de leyendas, tradiciones y recuerdos históricos de la ciudad de Niebla (Huelva). Lérida.

KEAY, S. (1991): «Peñaflor (La Viña). Informe preliminar», Anuario Arqueológico de Andalucial 1989, II: 289-284. Sevilla.

LERICHE, P. y Tréziny, H. (eds.) (1986): La Fortificatión dans l'histoire du Monde Grec. CNRS Colloque Intern. 614. Déc. 1982. CNRS. París.

Lindemann, G.; Niemeyer, H. G. y Schubart, H. (1972): "Toscanos, Jardín und Alarcón. Vorbericht über die Grabungskampagne 1971». Madrider Mitteilungen, 13: 125-157.

López PAlomo, L. A. (1979): "La cultura ibérica del valle medio del Genil». Córdoba.

- (1981): "Alhonoz: (Excavaciones de 1973 a 1978)". Noticiario Arqueológico Hispánico, 11: 33-188.

López RoA, C. (1978): "Las cerámicas alisadas con decoración bruñida». Huelva Arqueológica IV: 145-180.

Luzón, J. M. (1973): Excavaciones en Itálica. Estratigrafía en el Pajar de Artillo (E.A.E. 78). Madrid.

- (1975a): "Antigüedades romanas de la provincia de Huelva», en Huelva. Prehistoria y Antigüedad: 271-303. Madrid. Editora Nacional.

- (1975b): "Notas para una carta arqueológica de yacimientos romanos", en Huelva. Prehistoria y Antigüedad: 303-320. Madrid. Editora Nacional.

LlobREGAT, E. A. (1991): "Vias paralelas: templos y tumbas en Etruria y en Iberia». En J. Remesal y O. Musso (coords.): "La presencia de material etrusco en la Península Ibérica": 309-336. Public. Univer. Barcelona.

MuÑoz, A. (1986): “Las ánforas prerromanas de Cádiz. Informe preliminar". Anuario Arqueológico de Andalucia/1986. II. Actividades Sistemáticas: 471-478. Sevilla.

NiEmeyer, H. G. (1982): «El yacimiento fenicio de Toscanos: balance de la investigación 1964-1979». Actas de las Primeras Jornadas arqueológicas; sobre Colonizaciones orientales. Huelva, 1980. Huelva Arqueológica VI: 101130. Huelva

- (1986): «El yacimiento fenicio de Toscanos: urbanística

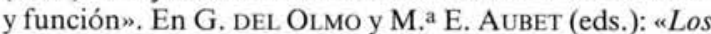
Fenicios en la Península Ibérica”, I: 109-126. Ed. Ausa. Sabadell.

Obermaier, H. (1924): «El Dolmen de Soto (Trigueros; Huelva)». Bol. Soc. Esp. Exc. año XXXII: 1-31. Madrid.

Pellicer, M. (1978): “Tipología y cronología de las ánforas prerromanas del Guadalquivir, según el Cerro Macareno (Sevilla)». Habis, 9: 365-400.
- (1982): “Las cerámicas del mundo fenicio en el Bajo Guadalquivir: evolución y cronología según el Cerro Macareno (Sevilla)". Phönizier im Westen Madrider Beiträge, 8: 371-406.

Pellicer, M. y Amores, F. (1985): «Protohistoria de Carmona. Los cortes estratigráficos CA-80/A y CA80/B". Noticiario Arqueológico Hispánico, 22: 55189.

Pellicer, M., Escacena, J. L. y Bendala, M. (1983): El Cerro Macareno. Excavaciones Arqueológicas en España, 124. Madrid.

Pingel, V. (1975): «Zur Vorgeschichte von Niebla (Prov. Huelva)", Madrider Mitteilungen, 16: 111-136.

Piñon, F. y BuENo, P. (1985): «Estudio de las colecciones de materiales procedentes de La Dehesa (Lucena del Puerto) y El Judio (Almonte). Testimonios sobre la ocupación neolítica del litoral onubense». Huelva Arqueológica, VII: 107-159.

RODERO, A. (1990): "Las anforas prerromanas en Andalucía". Madrid. Universidad Complutense. Tesis doctoral inédita.

Ros SAlA, M.a M. (1989): "Dinámica urbanística y cultura material del Hierro Antiguo en el valle del Guadalentín". Universidad de Murcia. Murcia.

Ruiz MatA, D. (1987): "Informe sobre las excavaciones sistemáticas realizadas en el yacimiento del Castillo de Doña Blanca (Puerto de Santa María, Cádiz)". Anuario Arqueológico de Andalucia/ 1986, II: 360-365. Sevilla.

- (1988): «El Castillo de Doña Blanca. Yacimiento clave de la protohistoria peninsular", Revista de Arqueologia, 85: 36-48. Zugarto Ed. S.A. Madrid.

- (1989): «Huelva: un foco temprano de actividad metalúrgica durante el Bronce Final». En «Tartessos. Arqueología Protohistórica del Bajo Guadalquivir»: 209-243. Ed. Ausa. Sabadell.

Ruiz Mata, D. BlázQuez. J. M. a y Martín de la Cruz, J. C. (1981): «Excavaciones en el Cabezo de San Pedro (Huelva). Campaña de 1978n. Huelva Arqueológica, V: 149-316. Huelva.

SHARON, I. (1987): "Phoenician and Greek Ashlar Construction Thechniques at Tell Dor, Israel" Bull of the American Schools of Oriental Research, 267: 21-42.

STERN, H. (1977): "The excavations at Tell Mevorach and the Late Phoenician elements in the architecture of Palestine". Bulletin of the American Schools of Oriental Research, 225: 17-26.

Terrero, J. (1952): "La «Tierra Llana» de Huelva. Estudio geográfico de la comarca». Estudios Geográficos, 49: 671-698.

- (1954): "La «Tierra Llana" de Huelva". Estudios Geográficos, 54: 5-58.

UNTERMANN, J. (1985): «Lenguas y unidades politicas del suroeste hispánico en época prerromana». En De Tartessos a Cervantes: 1-40; Köln.

VALLESPI, E. y otros (1986): "Nuevas atribuciones onubenses al Paleolítico Inferior y Medio". En "Huelva en su Historia. Miscelánea Histórica»: 43-56. Sevilla.

Whishaw, E. M. inéd.: Historia y Prehistoria de Niebla y de Riotinto. (Trabajo mecanografiado depositado en el Archivo Municipal de Niebla, Huelva).

YADIN, Y. y otros (1961): "Hazor III-IV. An account of the third and fourth seasons of excavations. 1957-1958m. Vol. de Láminas. The Hebrew University. Jerusalem. 